\title{
The Optimization Model of Searching the Wreckage
}

\author{
Xinglong Ren and Hong Fang* \\ College of Science, Huazhong Agricultural University, Wuhan, China \\ ${ }^{*}$ Corresponding author
}

\begin{abstract}
In order to search the wreckage, this paper establish the particle network model, in terms of Monte Carlo simulation method and the Bayesian theory. Based on analytic inverse extrapolation, we use Monte Carlo simulation method to simulate thousands of particles and the distribution of the aircraft crash position. According to the relationship between the successful search probability, the depth of seabed, and the size of crashed plane, the model is developed. We get the successful search probability in each grid. Based on Bayesian theory and above probability distribution, we renew the probability distribution in each grid, if no wreckage is found after the search is completed. To ensure the largest success probability for each search, we find the wreckage in the least time. In this paper, we set several positions of the wreckage. In this method to search 16 times, we minimize the total search area.
\end{abstract}

Keywords-the particle network mode; Monte Carlo simulation method; Bayesian theory; probability distribution

\section{INTRODUCTION}

On the morning of March 8, 2014, Malaysian Airlines MH370 lost touch with the control center, which has not been found yet. Nowadays, it has become the most mysterious event in this century and we were wondering where the lost Malaysian Airlines MH370 was. According to statistics, there have been almost 80 flights disappearing in the world since 1948. On the basis of the last contact with the ground plane position, nearly sixty percent of them disappeared in the sea. There is no doubt that the aircraft was crashed. However, it is too tough to find wreckage in the sea, which leads to their resting-place to become permanent mystery.

Bayesian theory of search utilized Bayesian statistical theory to search for the missing item, which has been repeatedly used to search and rescue missing ships.[1]It is a maximum contribution to mathematics that Bayesian solves the problem of how to calculate the inverse probability. The inverse probability is an important mathematical problem which is concerned about searching for the plane.

The Monte Carlo simulation method are commonly used to solve the problem of deterministic and random problems.[2] The factors of wind, currents and waves and so on all have influence on the movement of floats. If we have already known the position of the aircraft debris, then according to the correct model based on debris shape, buoyancy, wind, currents and waves and other data, we can calculate the trajectory of any debris.

\section{THE MODEL}

We propose some assumptions in order to build the model:1.The plane fragments then it crash into the sea;2.Floats in the sea at any time are in a state of balance;3.The radiation of waves and Coriolis force are ignored;4.The movement of these floats are uncorrelated.

\section{A. The Model Based on The Analysis of Floats}

The expression of the speed of the float in a certain position is

$$
\dot{v}_{\text {object }}=\mu_{\text {water }}+\alpha v_{\text {wind }}
$$

Where $\alpha$ denotes wind factor and its general value range is $0.01-0.05$.

Through the analysis of the float at sea, considering the float affected by the action of wind, flow and wave ${ }^{[3]}$, we can get

$$
M \frac{d V_{\text {object }}}{d t}+m f=F_{\text {wind }}+F_{\text {water }}+F_{\text {wave }}
$$

Where $m f$ denotes Coriolis force.

Based on the research achievement of Philippe Craneguy, the following equations are developed.

$$
\begin{aligned}
& F_{\text {wind }}=0.5 \rho_{a} C_{a} S_{a}\left|V_{\text {wind }}-\rho_{\text {object }}^{\rho}\right|\left(\rho_{\text {wind }}^{\rho}-\rho_{\text {object }}^{\rho}\right) \\
& F_{\text {water }}=0.5 \rho_{w} C_{w} S_{w}\left|\rho_{\text {water }}-v_{\text {object }}\right|\left(v_{\text {water }}-V_{\text {object }}\right) \\
& F_{\text {wave }}=0.5 \rho_{w} g C_{i w} L A^{2}
\end{aligned}
$$

Where $\rho_{a}, \rho_{w}$ denotes the density of air and sea water respectively, $S_{a}, S_{w}$ denotes the area that the target is exposed on the surface of water, and the area of the target beneath the surface of water respectively, $C_{a}, C_{w}$ denotes drag coefficient of air and flow respectively, $C_{i w}$ denotes the reflection coefficient of the incident wave, $A$ denotes wave wavelength, $L$ denotes target dimension, $g$ denotes the acceleration of gravity.

We assume that floats in the sea at any time are in a state of balance. Meanwhile, the radiation of waves and Coriolis force are ignored. We get

$$
F_{\text {wind }}=F_{\text {water }}^{[4]}
$$

Combing with the equations derived above, we obtain 


$$
v_{\text {object }}=v_{\text {water }}+\left(v_{\text {wind }}-v_{\text {water }}\right) \sqrt{\frac{\rho_{a} C_{a} S_{a}}{\rho_{w} C_{w} S_{w}}}
$$

\section{B. The Model Based on Monte Carlo Simulation Method}

Based on the optimization model of searching the debris, the relationship among the time of finding the plane $(t)$, the fall time of plane $\left(t_{0}\right)$ and the speed of floating debris $\left(v_{\text {object }}\right)$ can be developed. Then, we utilize Monte Carlo simulation method to count the starting point of the movement of debris.

Firstly, we treat the position found the debris as the datum point. Based on $t$ and $t_{0}$, we determine the power of wind and water which floating debris suffered at each time period. Using the vector overlay inverse method, we can get the position of floats in the former time. By above analysis, we can find the starting position of floats, that is the position where the plane crashed, as shown in FIGUREI.

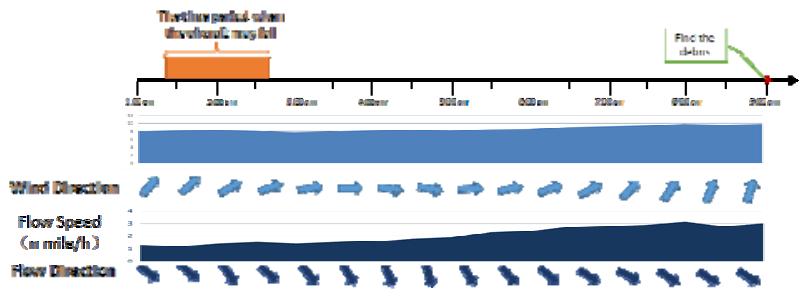

FIGURE I.

Next, this paper considers the error of the speed of flow, the error of direction of flow, the error of the speed of air, the error of direction of air and the time of plane crashed. Hence, the initial positions of debris are randomly distributed within a certain range and $E_{\text {WaterV }} 、 E_{\text {WaterD }} 、 E_{\text {WindV }} 、 E_{\text {WindD }}$ have normal distribution.

$$
\begin{aligned}
& E_{\text {WaterV }} \sim N\left(0, \sigma_{1}{ }^{2}\right) \\
& E_{\text {WaterD }} \sim N\left(0, \sigma_{2}{ }^{2}\right) \\
& E_{\text {WindV }} \sim N\left(0, \sigma_{3}{ }^{2}\right) \\
& E_{\text {WindD }} \sim N\left(0, \sigma_{4}{ }^{2}\right)
\end{aligned}
$$

According to the long-term statistics, we acquire $\sigma_{1} \sigma_{2} \sigma_{3} \sigma_{4}$.

$E_{t 0}$ is uniformly distributed.

$$
E_{t 0} \sim U\left(t_{1}, t_{2}\right)
$$

Where $t_{1}$ represents the time which the plane last contract with the the control center, $t_{2}$ represents the time which the aircraft ran out of fuel.

\section{The Model Based on Analytic Inverse Extrapolation}

We define $t_{1}$ as the time which the plane last contract with the the control center (In this time, the remaining petrol is expressed as Petrol ). And $\mathrm{t}_{2}$ is the time which the aircraft ran out of fuel (In this time, we can know the fuel consumption of plane in each $\mathrm{n}$ mile $\left(C_{\text {Petrol }}\right)$ and the speed of plane $\left(V_{t}\right)$ ). Then, we have

$$
t_{1}+\frac{\text { Petrol }}{C_{\text {Petrol }} V_{t}}=t_{2}
$$

As shown in FIGUREII, $\varphi$ is the true bearing which set to true north for $0^{\circ}, \varphi_{\text {Object }}$ is the true bearing of the speed of debris, $\varphi_{\text {Water }}$ is the true bearing of the speed of flow, $\varphi_{\text {Wind }}$ is the true bearing of the speed of wind. Based on previous equation $v_{\text {object }}=v_{\text {water }}+\alpha v_{\text {wind }}$, we disintegrate vector.

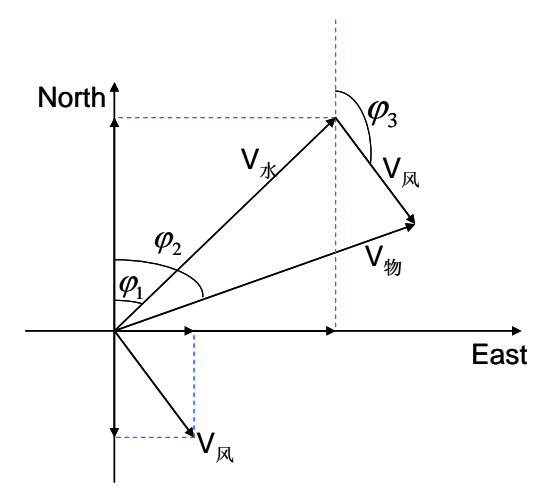

FIGURE II.

Then, we get

$$
\varphi_{\text {Object }}=\arctan \left(\frac{V_{\text {water }} \sin \left(\varphi_{\text {water }}\right)+\alpha V_{\text {Wind }} \sin \left(\varphi_{\text {Wind }}\right)}{V_{\text {water }} \cos \left(\varphi_{\text {water }}\right)+\alpha V_{\text {Wind }} \cos \left(\varphi_{\text {Wind }}\right)}\right)
$$

Afterwards, we push down from the moment of $t$ to forward and the time span is $\Delta t$.

We set the $X$ coordinate of the recent time node as

$$
\begin{aligned}
& X_{t-\Delta t}=X_{t}-V_{\text {Object }} \sin \left(\varphi_{\text {Object }}\right) \Delta t \\
& X_{t-\Delta t}=X_{t}-V_{\text {Object }} \cos \left(\varphi_{\text {Object }}\right) \Delta t
\end{aligned}
$$

Eventually, we simulate the thousands of the path of debris.

D. The Model Based on Bayesian Theory

The basic model is

$$
\begin{gathered}
r=1-p \\
P(A \mid B)=q \quad P(B)=p^{[5]}
\end{gathered}
$$

Where $A$ represents the event of the plane in the region, $B$ represents the event of finding the plane, $p$ represents the 
probability of the aircraft in this region, $q$ represents the successful search probability in the region, $r$ represents the probability of the aircraft in other region.

The probability of the main wreckage found successfully depends on the size of plane and the height of sea. Hence, this paper defines the following equation.

$$
q_{i}=0.8242 k_{1} \exp \left[-\left(\frac{\text { depth }_{i}-3.63}{82.89}\right)^{2}\right] \quad i=1,2, \Lambda, z
$$

Where $k_{1}$ represents volume correction factor, depth represents the depth of area of number $i$.

According to the results obtained by Monte Carlo simulation, we obtain

$$
p_{i}=\frac{n_{i}}{N} \quad i=1,2, \Lambda, z
$$

Where $n_{i}$ represents the simulated particle number in the area of number $i, N$ represents the total number of simulated particles.

$$
N=n+n_{2}+, \Lambda,+n_{i} \quad i=1,2, \Lambda, z
$$

Afterwards, we select the maximum probability area to conduct a search. If we do not search for the wreckage, the $p$ and $r$ will be renew. Therefore, we get

$$
\begin{gathered}
p^{\prime}=\frac{p(1-q)}{(1-p)+p(1-p)}=p \frac{1-q}{1-p q}<p \\
r^{\prime}=r \frac{1}{1-p q}>r
\end{gathered}
$$

After searching $n$ times, $p$ and $r$ are

$$
\begin{gathered}
p^{n}=\frac{p^{n-1}\left(1-q^{n-1}\right)}{\left(1-p^{n-1}\right)+p^{n-1}\left(1-p^{n-1}\right)}=p^{n-1} \frac{1-q^{n-1}}{1-p^{n-1} q^{n-1}} \\
r^{n-1}=r^{n-1} \frac{1}{1-p^{n-1} q^{n-1}}
\end{gathered}
$$

We will continue to research until finding the wreckage.

\section{RESULTS AND DISCUSSIONS}

\section{Step1: The Simulation of The Path of Debris}

By FIGUREIII, we can get the simulation of the paths of debris. The five different colored lines in the figure represent the paths of the five different debris at different locations. These five lines intersect at one point. Using this model, if we know all locations of the debris, we can obtain one point which they intersect at.

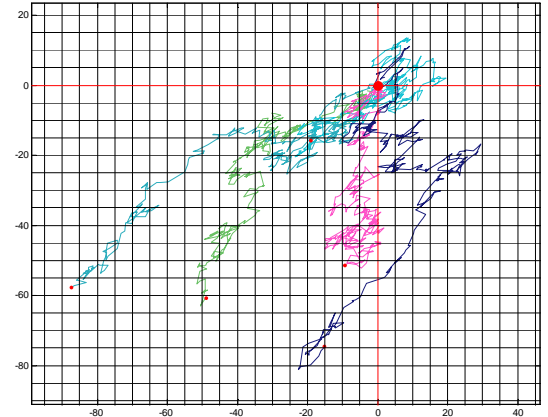

FIGURE III.

THE PROBABILITY OF THE AIRCRAFT IN THIS REGION

\section{Step2: The Calculation of $p$ In Each Square}

The float is defined as a single particle and the trajectory of which is a random process. We simulate thousands of particles and get position where they intersect at.

By the number of particles of each small square region divided by the total number of particles, we get the probability of each small square region, as shown in the FIGUREIV. Namely, we calculate the value of $P$ in each square.

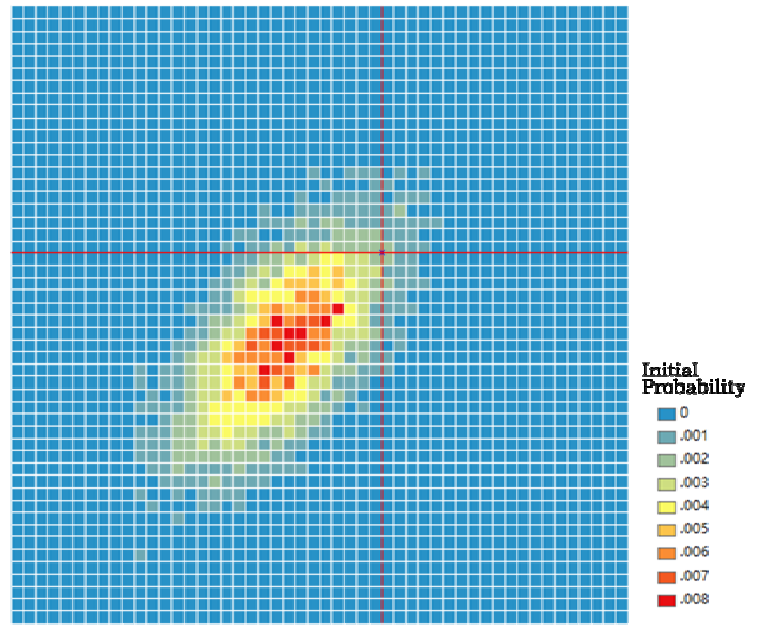

FIGURE IV.

THE PROBABILITY OF THE AIRCRAFT IN THIS

$$
\text { REGION }
$$

\section{Step3: The Calculation of $q$ In Each Square}

Utilizing the relationship between $q$ and the depth of seabed in our model, we calculate the value of $q$ in each square. The FIGUREV shows the successful search probability in the region. 


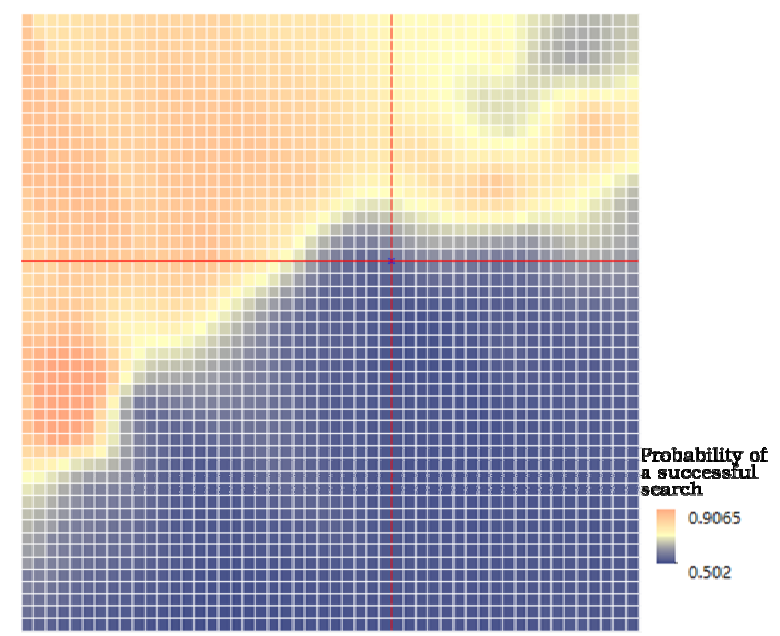

FIGURE V.

THE SUCCESSFUL SEARCH PROBABILITY IN THE REGION

\section{Step4: The Probability Changes in Some Area}

The FIGUREVI demonstrates the the probability changes at each time per particles. The different colored lines represents the probability change lines of different particles.

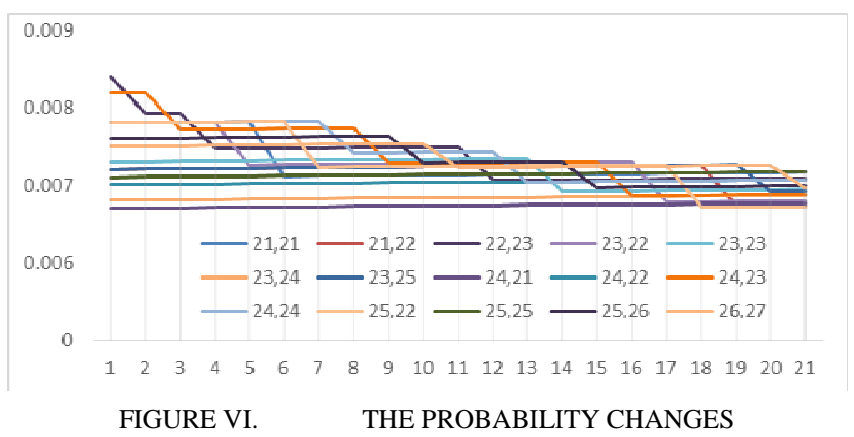

In this paper, we set several positions of the wreckage. In this method to search 16 times, we minimize the total search area.

\section{CONCLUSIONS}

Using this model, the space probability distribution of wreckage and the successful search probability can be calculated. Based on analytic inverse extrapolation, we use Monte Carlo simulation method to simulate thousands of particles and the distribution of the aircraft crash position. According to the relationship between the successful search probability, the depth of seabed, and the size of crashed plane, the model is developed. We get the successful search probability in each grid. Based on Bayesian theory and above probability distribution, we renew the probability distribution in each grid, if no wreckage is found after the search is completed. To ensure the largest success probability for each search, we find the wreckage in the least time. In this paper, we set several positions of the wreckage. In this method to search 16 times, we minimize the total search area. The optimization model has practical application significance, which can minimize the total search area and the total search time.

\section{REFERENCES}

[1] Wikipedia.2013.Bayesian search theory. http://zh.wikipedia.org/zhcn/\%E8\%B4\%9D\%E5\%8F\%B6\%E6\%96\%AF \%Е6\%90\%9C\%Е7\%B4\%A2\%Е7\%90\%86\%Е8\%AE\%BA.

[2] Ping Qiu.Sea best search area and the search method of the research [D]. Dalian Maritime University 2006.

[3] Smith,S.D. Coefficients for sea surface wind stress, heat flux and wind profiles as a function of wind speed and temperature. Journal of G.

[4] Wu,J. Wind-stress coefficients over sea surface near neutral conditions A revisit. Journal of Physical Oceanography. 1980.

[5] Stone, Lawrence D. The Theory of Optimal Search, published by the Operations Research Society of America, 1975. 